\title{
Study on Fire Station Layout Model with Urban Road-Unobstructedness
}

\author{
Lei Zhang \\ College of Management \\ Wuhan University of Science and Technology \\ Hubei, China \\ 1358118237@qq.com
}

\author{
Tao Chen \\ College of Management \\ Wuhan University of Science and Technology \\ Hubei, China \\ 2763065171@qq.com
}

\begin{abstract}
It is found that the random change of traffic flow in the road network will affect the passing efficiency of vehicle in most cases. In order to enhance the capability of cities of coping with sudden events, this paper is intended to introduce the concept of road-unobstructedness to correct the traffic impedance encountered by fire engines. What's more, this study also redefine the fairness and put forward an improve fire station layout model based on the comprehensive consideration of economic, social and environmental factors, to provide a new viable analysis approach for making optimal decision on fire station location based on comprehensive consideration. The results show that the model can improve the efficiency of $25 \%$ and reduce the average travel time of fire engines.
\end{abstract}

Keywords-Fire station; road-unobstructedness; traffic; location

\section{INTRODUCTION}

Presently, China's construction of urban public fire control facility fall behind its urban development, and it is especially true for fire station, the important part of urban public fire control facility. The fire stations in most cities have the problems of small number, sparse distribution and overlarge area of responsibility. For example, the area of responsibility of a fire station in Guangzhou is $29 \mathrm{~km}^{2}$ on average, and that in Shanghai reaches up to $121.9 \mathrm{~km}^{2}$. The location and layout of fire stations are key factors deciding whether rescue service can be provided promptly. It is one of the important tasks of urban public fire control facility construction to increase new fire stations so as to raise the efficiency of fire rescue and reduce losses caused by fire.

There are many factors influencing location of fire station, including traffic condition, physiographic condition, road condition, land price, and urban function division. Obviously, for some factors mentioned above, only objective analysis can be made, while for other factors, quantitative analysis can be realized. In fact, the key to minimizing the loss due to fire is that fire brigade can arrive at the scene of fire promptly. Therefore, the running time of vehicle is usually taken as the criterion for judging the location of fire station in most researches. The research in this paper also follows this criterion.

Besides, fire station is a special public facility, so its location should be based on comprehensive consideration of multiple factors, such as spatial distribution of population, distance accessibility, land suitability, etc. Moreover, the conflicts and interaction among the factors also should be considered. In this paper, these factors will be taken into full consideration, so as to design a scientific model.

In reality, vehicles will encounter various interferences, and the actual speed will be slower than the design speed. Sometimes, traffic jams will occur, so that vehicles have to go round and the routine will be extended. Based on this, roadunobstructedness is introduced to correct the shortest routine, so as to obtain a more reliable model.

\section{LITERATURE REVIEW}

About location of fire station, various researches have been made based on the model theory and related algorithm both at home and abroad. Helly[1] studied the urban system model, and built a planar model of location of fire station with minimizing the emergency response time as the primary objective. Masood et al[2] considered that besides running time and traveling distance, some other factors also should be taken into account, such as expenses, policy and fire water supply, and built a multi-objective mathematical programming model according to the conflicting objectives to be considered in location of fire station.

In recent years, many Chinese scholars also have made researches on location of emergency facilities. Fang Lei and $\mathrm{He}$ Jianmin[3] put forward a mathematical model of minimizing all-in cost while meeting the characteristic of time urgency of emergency systems. Han et al[4] discussed the location of emergency service facilities subject to deadline; Ma Yunfeng[5] et al studied time satisfaction-based covering location problem, set covering location problem and maximum covering location problem, and solved the problems with different algorithms. Considering the occurrence of fire is uncertain in reality, some scholars start to study location of fire station with demand uncertainty under consideration. Wang Dingwei[6] et al proposed an emergency rescue center location model based on probability of disaster occurrence, disaster diffusion function and rescue function, and solved it with the embedded heuristic genetic algorithm; In Literature[7], about the location of emergency rescue facilities in the case that both the needs in the scene waiting for rescue and the traffic condition of the traveling path are uncertain, the expected value method and stochastic simulation were employed to quantize the quantity demanded of goods and materials, road capacity and other uncertain factors, and a set covering location model with cost 
minimization as the objective was built. In Literature[8], about the location of roadside assistance facilities at basic level, the analytical hierarchy process and grey relation method were employed to abstract the scene waiting for rescue, alternative rescue point and the path there between, and so on, and a multiobjective location model with cost minimization and shortest rescue time as the objectives was built.

Fire station is also a kind of public facility, and some other factors should be taken into account in its location. There are many Chinese scholars having made related studies. Wei Tong[9], about the location problem of multi-service center, built a mixed integer programming model. Dai Ying[10], about the location and vehicle routing optimization of emergency rescue center for handling urban public sudden events, put forward a decision of integrating emergency supplies distribution center location with delivery vehicle route arrangement, and built a fuzzy multi-objective location and route optimization model.

\section{MODEL DESCRIPTION}

\section{A. Road-unobstructedness}

To ensure the unobstructedness and reliability of urban road network is the main objective of road network planning or reorganization and expansion. Unobstructedness means that vehicles can run smoothly, which mainly depends on whether the road capacity can address the traffic demand. Since traffic demand (D) and road capacity (C) are of high randomness, there is no road network that is absolutely unobstructed. By referring to the reliability theory, unobstructedness reliability can be defined as: the probability of the road traffic running state being able to meet the unobstructedness state within specific period and on the premise of road network in normal service condition. The unobstructedness reliability of road unit can be calculated (probability calculation) with a traffic supply and demand distribution density function, which can be obtained via trip survey and road traffic analysis.

For application of the method mentioned above, a large quantity of statistical data is required, which increases the workload of calculating unit unobstructedness reliability. In fact, unobstructedness reliability and road unit saturation are closely related. To facilitate road network optimization, Formula (1) can be adopted to solve the unobstructedness reliability of each road unit simply, wherein $\pi_{i}$ stands for the unobstructedness reliability of the ith road unit.

$$
\pi_{i}=\left\{\begin{array}{cc}
1 & D_{i} / C_{i}<0.1 \\
1-D_{i} / C_{i} & 0.1 \leq D_{i} / C_{i}<0.9 \\
0.1 & D_{i} / C_{i} \geq 0.9
\end{array}\right.
$$

According to Formula (1), the lower the saturation D/C of road unit is, the more unobstructed the unit is, and vice versa; if $\mathrm{D} / \mathrm{C}$ is larger than 0.9 , it is deemed that the unit is highly unreliable, and a small value (0.1) is given to stand for the unobstructedness reliability of the unit.

Road-unobstructedness is the ability to reflect the road. For convenience, the reciprocal $\rho$ of $\pi$ is taken to stand for the resistance factor of road, that's namely:

$$
\rho=1 / \pi
$$

\section{B. Facility Location Model}

According to the characteristics of location problems of emergency rescue facilities for handling sudden events stated above, a multi-objective decision-making model is put forward in this paper. First of all, it is hypothesized that since emergency facilities must cover specific area, the distance between the location and the corresponding area is required to be within a certain range, so as to facilitate initial screening of alternative points. Besides, it is also hypothesized that a block is a point in the network graph, and the roads linking blocks are the arcs of the network graph.

Based on the above hypothesis, the specific multi-objective programming model of fire station location is as below:

$$
\begin{gathered}
\min F_{1}=\sum_{j \in J} x_{j} y_{j}+\sum_{i \in I} \sum_{j \in J} \rho_{i} d_{i j} n_{i j} \\
\min F_{1}=D_{0} \\
\min T=\sum_{i \in I} \sum_{j \in J} \frac{\rho_{i} d_{i j} z_{i j}}{V_{i}} \\
\sum_{j \in J} y_{j}=Q \\
z_{i j}-y_{j} \leq 0 \\
\sum_{j \in J} \rho_{i} d_{i j} z_{i j} \leq q_{i} D_{0} \\
y_{j} \in\{0,1\}, Z_{i j} \in\{0,1\}, \forall i \in I, j \in J
\end{gathered}
$$

Wherein,

- $x_{j}$ refers to the fixed construction cost of fire station at Point j;

- $n_{i j}$ to the quantity of vehicles sent from fire station to fire scene;

- $d_{i j}$ to the distance from Point $\mathrm{j}$ to fire scene $\mathrm{i}$;

- $V_{i}$ to the normal running speed of vehicle $\mathrm{i}$;

- $\mathrm{Q}$ to the predetermined quantity of emergency rescue equipment;

- $q_{i}$ to the minimum quantity of service facilities required by area i;

- $D_{0}$ to the fairness degree; I to the set of demand points;

- $\mathrm{J}$ to the set of alternative points;

- $y_{j}$ and $z_{i j}$ are variables ranging from 0 to 1 ,

in which

$$
y_{j}=\left\{\begin{array}{l}
1, \text { If the fire station built at locations in } \mathrm{j} \\
0,
\end{array}\right.
$$




$$
z_{i j}=\left\{\begin{array}{lc}
1, & \text { If } \mathrm{j} \text { service for fire station } \mathrm{i} \\
0, & \text { else }
\end{array}\right.
$$

Model analysis: Formula (3) shows cost minimization of facility construction, including land cost and transportation cost. The transportation cost is mainly related to the number of sent vehicle and distance. Formula (4) and Formula (8) show the fairness degree of facility namely minimize the maximum distances from different alternative points to each demand point. Formula (5) shows the minimum traveling time of vehicle with road-unobstructedness reliability under consideration. Formulas (6) and (7) show that the number of facility points serving the demand points is not more than $\mathrm{Q}$.

\section{RESUlTS}

For purpose of model verification, case study of emergency rescue facility planning in an area is made. Considering there are 8 blocks in this area, the local government plans to select three points out of five alternative points (A, B, C, D, E) for construction of fire station. Please see Table 2 for the travelling distance from the alternative points to the block centers, and Table 3 for the road impedance coefficients between fire stations to different block centers.

TABLE I. TRAVELling DistanCE From Alternative Fire Stations TO BLOCK CENTERS (KM)

\begin{tabular}{|c|c|c|c|c|c|c|c|c|c|}
\hline Demand block & $\mathrm{i}$ & 1 & 2 & 3 & 4 & 5 & 6 & 7 & 8 \\
\hline \multirow{4}{*}{$\begin{array}{c}\text { Alternative } \\
\text { facility j }\end{array}$} & $\mathrm{A}$ & 8 & 5 & 8 & 10 & 2 & 4 & 6 & 7 \\
\cline { 2 - 11 } & $\mathrm{B}$ & 15 & 12 & 11 & 11 & 8 & 7 & 5 & 7 \\
\cline { 2 - 11 } & $\mathrm{C}$ & 16 & 12 & 14 & 12 & 13 & 11 & 13 & 11 \\
\cline { 2 - 10 } & $\mathrm{D}$ & 12 & 11 & 10 & 12 & 8 & 6 & 7 & 6 \\
\cline { 2 - 10 } & $\mathrm{E}$ & 6 & 4 & 5 & 9 & 6 & 5 & 3 & 7 \\
\hline
\end{tabular}

TABLE II. ROAD IMPEDANCE COEFFICIENT BETWEEN ALTERNATIVE FIRE STATIONS AND DIFFERENT BLOCK CENTERS

\begin{tabular}{|c|c|c|c|c|c|c|c|c|}
\hline \multirow{2}{*}{$\begin{array}{c}\text { Alternative } \\
\text { site }\end{array}$} & \multicolumn{10}{|c|}{ Block } \\
\cline { 2 - 9 } & $i_{1}$ & $i_{2}$ & $i_{3}$ & $i_{4}$ & $i_{5}$ & $i_{6}$ & $i_{7}$ & $i_{8}$ \\
\hline$j_{1}$ & 2 & 1.5 & 3 & 2.1 & 3 & 2.4 & 2.1 & 2 \\
\hline$j_{2}$ & 2.2 & 1.8 & 1.9 & 1.5 & 2.5 & 1.7 & 1.6 & 1.4 \\
\hline$j_{3}$ & 2.3 & 2.5 & 1.6 & 1.9 & 1.5 & 2.5 & 2.1 & 1.8 \\
\hline$j_{4}$ & 2 & 1.7 & 2.4 & 2.1 & 2.3 & 2.2 & 2.4 & 2.1 \\
\hline$j_{5}$ & 2.1 & 2.3 & 1.9 & 1.8 & 1.7 & 2.1 & 2.3 & 2.4 \\
\hline
\end{tabular}

TABLE III. Weighted Distance BetWeEn EACH Alternative Site to EACH BLOCK CENTER (KM)

\begin{tabular}{|c|c|c|c|c|c|c|c|c|c|}
\hline \multirow{2}{*}{ Alternative site } & \multicolumn{10}{|c|}{ Block } \\
\cline { 2 - 10 } & $i_{1}$ & $i_{2}$ & $i_{3}$ & $i_{4}$ & $i_{5}$ & $i_{6}$ & $i_{7}$ & $i_{8}$ & Total \\
\hline$j_{1}$ & 18.4 & 9 & 26.4 & 25 & 5.8 & 10 & 13.8 & 13.3 & 121.7 \\
\hline$j_{2}$ & 31.5 & 22.8 & 22 & 18.7 & 20.8 & 11.9 & 9 & 10.5 & 147.2 \\
\hline$j_{3}$ & 38.4 & 30 & 23.8 & 21.6 & 20.8 & 28.6 & 26 & 20.9 & 210.1 \\
\hline$j_{4}$ & 27.6 & 19.8 & 26 & 27.6 & 20 & 11.4 & 17.5 & 12 & 161.9 \\
\hline$j_{5}$ & 15.6 & 10 & 12.5 & 17.1 & 12 & 9.5 & 6 & 15.4 & 98.1 \\
\hline
\end{tabular}

(1) Suppose the normal running speed of vehicle is $60 \mathrm{Km} / \mathrm{h}$, and then the figures in Table 3 stand for travel time.
(2) Based on survey on actual land price and construction cost, suppose the fixed cost of the alternative sites are: $\mathrm{FC}_{j}=(120,100,130,110,140)$, since variable cost depends on the distance and fire severity, to facilitate calculation, it is supposed that each fire station only sends one vehicle to fire scene, and then the total cost is:

$$
\mathrm{TC}_{j}=(241.7,247.2,340.1,271.9,238.1) \text {. }
$$

(3) To show fairness, the maximum distance from each alternative site to each block center is taken, and then the fairness set of the alternative points is: $F=(10,15,16,12,9)$

Generally, a multi-objective model will be transformed into a single-objective model by taking different weights for different objective functions. The weights taken for this paper are: $\mathrm{f}_{1}=0.15, \mathrm{f}_{2}=0.4, \mathrm{f}_{3}=0.45$, and a single-objective function can be established, as below:

$$
\mathrm{Z}_{1}=0.15 \times 241.7+0.4 \times 10+0.45 \times 121.7=95.02
$$

In a similar way, the function values of the rest four schemes can be solved, which are $\mathrm{Z}_{2}=109.32, \mathrm{Z}_{3}=151.96$, $\mathrm{Z}_{4}=118.44$ and $\mathrm{Z}_{5}=83.46$.

According to the calculation, the alternative site of emergency rescue facility should be located in the $5^{\text {th }}$ block. And the previous traffic time is: $\mathrm{TP}_{\mathrm{j}}=(89.2,112.1,150.5$, $123.6,75.2$ ), so this model will reduce the passage time of $25 \%$.

\section{CONCLUSION}

City is a place where social people, logistics, capital flow, technological resources, and information flow are most heavily concentrated. Under weather effect, geological influence and social factor, and with the rapid development and expansion of cities, more and more unexpected events occur in cities frequently, and the demands for emergency service are constantly occurring and changing. It is extremely urgent to enhance the capability of cities of coping with sudden events. Fire station is an important emergency service facility, and its layout and plan should be made through scientific analysis. For various reasons, however, the fire stations in China are mainly planned and designed on the basis of experience, so that urban fire stations are assigned with overlarge area of responsibility. The layout is irrational. Besides, due to failure to comprehensively consider the influencing factors of location, vehicle always will encounter interference on the way of rescue from time to time. For example, it is found that the random change of traffic flow in the road network will affect the passing efficiency of vehicle in most cases. So in this paper, road impedance coefficient is introduced out of consideration of actual situation to make the model more reliable, and economic social and environmental factors are comprehensive consideration. At last the method feasibility is verified via analysis of examples.

\section{REFERENCES}

[1] HELLY W. Urban systems models, New York: Academic Press, 1975.

[2] MASOOD B, AMRK M, “A multi-objective model for locating fire station,” European Journal of Operational Research, 1998, vol. 110, pp. $243-260$. 
[3] Fang Lei, He Jianmin. Emergency System Optimal Location Modela dn Algorithm within A Specified Deadline [J]. Journal of Industrial Engineering and Engineering Management, 2004, (1): 48-51.(In Chinese)

[4] Han Qiang. Simulated Annealing Algorithm of Multi-objective Emergency Facility Location Problem [J]. Computer Engineering and Applications, 2007, (30): 182-184. (In Chinese)

[5] Ma Yunfeng. Study on Set Covering Problem Based on Time Satisfaction and Applications of Greedy Algorithm [J]. Journal of Wuhan University of Science and Technology, 2006 (6): 631-635. (In Chinese)

[6] Wang Dingwei, Zhang Guoxiang. Model and Algorithm of Sudden Disaster Assistance Center Location Optimization [J]. Journal of Northeastern University, 2005, (10): 953-956. (In Chinese)
[7] Tao Sha, Hu Zhihua. Emergency Rescue Location Problem with Uncertain Demands and Logistics Network [J]. Journal of Computer Applications, 2012, 32(9): 2534-2537. (In Chinese)

[8] Wu Yanhua, Wang Fuzhang, Li Fang. Railway Rescue Base Hierarchical Planning Location Model [J]. Journal of Traffic and Transportation Engineering, 2013, 13(3): 86-93. (In Chinese)

[9] Wei Tong, Gen Na, Jiang Zhibin, et al. Multi-service Multi-facility Location Problem with Determined Demands [J]. Industrial Engineering and Management, 2014(1): 47-52. (In Chinese)

[10] Dai Ying, Ma Zujun. Random Location-Path of Emergency Logistics System [J]. Systems Engineering-Theory Methodology Application, 2012, 21(2): 212-217. (In Chinese) 